\title{
On crystals in the cavities of topaz
}

\section{Sir D. Brewster}

To cite this article: Sir D. Brewster (1845) On crystals in the cavities of topaz, Philosophical Magazine Series 3, 26:174, 462-462, DOI: 10.1080/14786444508645173

To link to this article: http://dx.doi.org/10.1080/14786444508645173

$$
\text { 册 Published online: } 30 \text { Apr } 2009 .
$$

6 Submit your article to this journal $\pi$

LII Article views: 2

Q View related articles $\asymp$ 
allow of the formation of a secondary product; the same effect may be produced with carbonate of lead.-Journ. de Pharm. et de Ch., Mars 1845.

on PIAUZite, a Mineral Resiñ. BY M. haidinger.

Colour, blackish-brown; streak, yellowish-brown; massive; lustre, resinous ; fracture, imperfect conchoidal ; translucent on the thin edges; feeble lustre in cut places; hardness $=1.5$; specific gravity, $1 \cdot 220$.

Chemical properties. $\rightarrow$ At about $590^{\circ}$ Fahr. it inflames; it burns at a somewhat higher temperature with a peculiar aromatic smell, with much flame and soot, leaving an ash. It is completely soluble in ether and in potash; it is almost entirely soluble in anhydrous alcohol, but less soluble in alcohol containing water: Fuming nitric acid converts the colour of the dark brown resin into yellowishbrown. Heated in a glass tube, there is distilled from it a yellowish oily fluid, which has an acid reaction. In its common state it contains $\mathbf{3 . 5}$ per cent. of hygroscopic water; when dry it yields $\mathbf{5 . 9 6}$ per cent. of ash.

It occurs in veins from one inch to two inches wide, traversing brown coal and bituminous wood, in a brown coal deposit, in the meighbourhood of Piauze, north of Newstadtl, in Carniola.

Its easy inflammability, and the abundance of soot which it deposits during burning, cause it to be used for giving the black colour to cast-iron ware.-Poggendorff's Annalen. Jameson's Journal.

ON CRYSTALS IN THE CAYITIES OF TOPAZ. BY SIR D. BREWSTER.

The author gave a brief notice to the British Association of the discovery which he had made, about twenty years ago, of two new fluids in the cavities of topaz, and other minerals.

One of these fluids is very volatile, and so expansible, that it expands twenty times as much as water with some increase of temperature. When the vacuities in the cavity which it occupies are large, it passes into vapour; and in these different states he had succeeded in determining its refractive power, by measuring the angles at five feet. Total reflexion takes place at the common surface of the fluid of the topaz. The other fluid is of a denser kind, and occupies the angles and narrow necks of cavities. The cavities, however, in which the soluble crystals are contained, are of a different kind. 'They (viz. the cavities) are imperfectly crystallized, and thus they exist in specimens of topaz which contain the cavities with the two new fluids ; they contain none of the volatile and expansible fluid, which is doubtless a condensed gas. The crystals which occupy then are fiat and finely crystallized rhomboids. When heat is applied, they become rounded at their edges and angles, and soon disappear. After the topaz has cooled, they again appear, at first like a speck, and then recrystallize gradually, sometimes in their original place, but often in other parts of the cavity, their place being determined by the mode in which the cooling is applied.-Jameson's Journal, April 1845. 